will be located near Honolulu on a government reservation originally set apart by the provisional government for the use of an experiment station. It is intended to make the work there supplementary to that of the experiment station which has been maintained by the Hawaiian sugar planters, and attention will be given to other field crops and the development of animal industry and horticulture. Jared G. Smith, recently in charge of the Section of Seed and Plant Introduction of this department, has been placed in charge of the Hawaii station, and will take up the work there about the middle of April. Fifty thousand dollars was appropriated to continue the irrigation investigations, and $\$ 20,000$ for nutrition investigations, the latter being an increase of $\$ 2,500$.

The Division of Statistics receives $\$ 156$,160 , the same as last year, the Division of Entomology $\$ 36,200$, and the Division of Biological Survey $\$ 32,800$. The fund for publications is increased by $\$ 50,000$ for farmers' bulletins and a small amount for distribution, making the total for the Division of Publications $\$ 198,020$ aside from the general printing fund, $\$ 110,000$. Other appropriations are as follows : seeds, $\$ 250$,000 , exclusive of the $\$ 20,000$ mentioned for seed and plant introduction, an increase of $\$ 100,000$; library, $\$ 16,000$; public-road inquiries, $\$ 20,000$, an increase of $\$ 6,000$; investigating the production of domestic sugar, $\$ 5,000$; Arlington farm, $\$ 10,000$; office of the Secretary, $\$ 71,670$; Division of Accounts, $\$ 18,900$; Museum, $\$ 2,260$, and contingent expenses, $\$ 37,000$. The grand total, including the regular appropriations for the experiment stations, is $\$ 4,582,420$, an increase of $\$ 558,920$ over last year.

An important item of the appropriation act is the authorization of the Secretary of Agriculture to submit plans and recommendations for a fireproof agricultural building, to be erected on the grounds of the Department, and appropriating $\$ 5,000$ for the preparation of such plans. The Department long since outgrew its original accomodations, and for years has been badly cramped for room. The present main building has been condemned as unsafe, and from the nature of its construction the risk of fire has always to be met. Besides erecting a number of small buildings, which are mere temporary makeshifts, it has been necessary to rent several residences in the neighborhood and adapt them to laboratory and office purposes. Laboratory buildings for the Division of Chemistry and the Bureau of Animal Industry have been specially erected by private parties and rented to the Department. The amount now paid for rental for these buildings, together with the additional expense required for watchmen, aggregates about $\$ 10,000$ annually. The position to which the Department has now attained, the demands of its work, and the safety of its library records and collections, make a modern agricultural building a practical necessity if not an imperative need.

E. W. Allen.

\section{THE REDUCTION TO ABSURDITY OF THE ORDINARY TREATMENT OF THE SYLLOGISM,}

THe traditional treatment of the syllogism errs both by redundancy and by insufficiency-that is to say, the validity of the syllogism can be tested by a far simpler. method of procedure, and, on the other hand, the ordinary method fails of application to a vast number of pairs of propositions which are nevertheless the premises of a valid syllogism. In the first and second moods of the first figure the syllogism is in what may be called its primitive form-it is doubtless the only form in which it is used by children and savages; but there is another form, in which negative modes of expression are given free play, which is far 
superior to it in facility of manipulation. This superiority has its source in the fact that of the eight (not four, to which the ordinary logic has reduced the forms of speech) propositions necessary to a complete description of the universe,-
$a$. all $a$ is $b$,
$\bar{u}$. none but $a$ is $b$,
$\bar{i}$. no $a$ is $b$,
$\bar{a}$. not all $a$ is $b$,
$u$. some besides $a$ is $b$,
o. all but $a$ is $b$,
$i$. some $a$ is $b$,
$\overline{0}$. not all but $a$ is $b$,

it is the last four that possess the great advantage of being symmetrical (that is, of having subject and predicate amenable to the same rules of manipulation), and of these it is ' no $a$ is $b$ ' and ' some $a$ is $b$ ' that possess the other advantage of naturalness. These last should therefore be regarded as the canonical form of the proposition; and correspondingly, the ideal form of the syllogism is that in which it appears as a atatement of the impossibility of concurrence of the premises and the denial of the conclusion of the ordinary syllogism. The canonical form of the syllogism is therefore this :

$\begin{array}{ll} & \text { no } a \text { is } b, \\ \text { and } c \text { is non- } b, & \text { some } a \text { is } c\end{array}$

are inconsistent (or cannot all three be true together). This may be called the Inconsistency, or the Incompatibility, or, perhaps, the Antilogism. But in this all three propositions play an exactly similar rôlethere is no distinction between premises and conclusion, and it is therefore the one single form to which every syllogism may be at once reduced, provided we (1) express every universal proposition in the negative form, no $p$ is $q$, (2) express every particular proposition in the affirmative form, some $r$ is $s$, and also (3) deny the conclusion. When thus reduced to the form of an inconsistency, the rule for validity is this: of the three propositions, two are universal and one is particular; each two propositions have one and only one term in common; the term common to unlike propositions appears with like signs and the term common to like propositions appears with unlike signs. (Thus in the above typical form, $b$ and non- $b$ are common to the two universal propositions, but $a$, or c, of like quality, are common, respectively, to the particular and either universal.)

Any given statement of fact may be expressed in terms of any one of the four different copulas given above, or again, with the aid of the special terms the non-existent and the existent ( 0 and $\infty$ in Symbolic Logic), it may be expressed in four different ways with one and the same copula; thus

$$
\begin{array}{ll}
\text { all } a \text { is } b, & \text { nothing is } a \text { and } \bar{b}, \\
\text { all } \vec{b} \text { is } \vec{a}, & \text { everything is } \vec{a} \text { or } b,
\end{array}
$$

are four different forms of one and the same statement of fact (expressed in the four possible combinations of two terms and their negatives); but in the two symmetrical copulas (no $a$ is non- $b$, all but non- $a$ is $b$ ) $*$ the four forms all become practically identical. There are therefore ten $(4+4+1+1)$ essentially different ways of saying one and the same thing. As each proposition of the Inconsistency can be expressed in any one of these different ways, and again as each Inconsistency can appear in the form of the universal or of the particular syllogism, the total number of possible syllogisms (when full latitude is given to mode of expression) is two thousand $(10 \times 10 \times 10 \times 2)$. An example of one of these outlying forms is this : none are athletic and unhealthy, none are healthy and unhappy, hence all are either

\footnotetext{
* It is, to a certain extent, matter of taste whether no $a$ is b, nothing is both $a$ and $b$, no $b$ is $a, \quad a$ which is $b$ is non-existent,
}

be regarded as different forms or not,-and so 'all but $a$ is $b$,' etc. If it be preferred to consider them as different, then the entire number of propositional forms is $\mathbf{1 6}$ instead of $\mathbf{1 0}$ and the number of different syllogisms is $16 \times 16 \times 16 \times 2=8192$. 
happy or non-athletic. Any one of these two thousand forms can be at once tested as regards its validity by the above ' Rule for the Inconsistency.'

\section{Christine Ladd Franklin.}

\section{AMERICAN CHEMICAL SOCIETY.}

The American Chemical Society will celebrate the 25th anniversary of its foundation in the city of New York, on Friday and Saturday, April 12th and 13th. Prominent chemists from every portion of the United States are expected to participate in the festivities which include a presentation of the history and achievements of the Society, its present scope of work and influence and a general review of the progress of chemical science in this country during the past twenty-five years. The present condition of the science of chemistry will also be shown, and the extent of its applications to the various industries.

The American Chemical Society is an outgrowth of a meeting of American chemists held in Northumberland, Penn., August 1, 1874 , to celebrate the centennial of the discovery of oxygen by Sir Joseph Priestley. The large body of eminent chemists there assembled believed that the time had come for the formation of a permanent society, which should be representative of American chemists and their work, as the foreign chemical societies are of the chemists of their respective countries.

It was not until the year 1876 , however, that this idea took definite form in the establishment of the American Chemical Society. In the early part of that year the Society was organized, and in 1877 it was incorporated under the laws of the State of New York.

The first president was that distinguished chemist and physiologist, Dr. John W. Draper, of the City of New York, whose researches in spectrum analysis and pioneer work in the production of the daguerreotype and photograph will never be forgotten.
From the beginning the Society has published regularly a journal of its proceedings, including papers and discussions. Many of the leading chemists of this country have been enrolled in its membership ; prominent chemical manufacturers have been among its associates; and not a few of the names of foreign chemists of distinction have been upon its roll, either as active or as honorary members.

About ten years ago very radical changes were effected in the methods and operations of the Society, and the results that have followed have proved the wisdom of the steps thus taken. The important features of the present plan of organization and operation are as follows :

1. Local sections are established in different parts of the country, and the presiding officers of these sections constitute the vice-presidents of the Society.

The following is a list of these local sections up to date : Rhode Island, Cincinnati, New York, Washington, Lehigh Valley, Chicago, Nebraska, North Carolina, Columbus, North Eastern (headquarters in Boston), Philadelphia, Michigan and Kansas City.

2 . The general management of the Society is entrusted to a broadly representative council which includes all the past presidents of the Society, one or more representatives from each local section and twelve councilors elected by the membership at large.

3. Two general meetings of the Society are held each year in different localities with a view of increasing interest in the Society and stimulating activity among the chemists in various sections of the country by bringing them into closer acquaintance with one another and into a knowledge of the various interests with which they are connected. The summer meeting is held with that of the American Association for the Advancement of Science, and the win- 